\title{
Sigla explicantur.
}

$A=$ Codex Argentinensis, completus Conf. pag. 663.

$B=$ - Basileensis, lib. $I-V$ continens. Conf. pag. 664 .

$C=$ - Colbertianus sive Parisius I, completus. Conf. pag. 664.

$J=$ Editio a Jammy 1651 curata. Conf. pag. 671 .

$L=$ Codex Balliolensis Oxfordiensis, completus. Conf. pag. 665 .

$M$. $=$ Meyeri adnotationes.

$O=$ Codex Orielensis, vilïs. Conf. pag. 666 .

$P=\quad$ Petri domi Cantabrigiensıs, inde a lib. I fine (\$. 205-206) integer. Conf. pag. 666.

$\boldsymbol{V}=$. S. Victoris vel Parisius II, completus. Conf. pag. 665.

$\boldsymbol{V}$ ind. =: Codicis eiusdem index secundus. Conf. pag. 665 .

$Z=$ Editio a Zimara 1517 curata. Conf. pag. 669.

Codices adhibiti sunt sex, neglecto septimo (O), quorum quinque, $A B C L V$, librum $I$, cuncti sex libros $I I-\nabla$, quinque iterum, ACLPV, libros VI-VII exhibent.

Alb. = Alberti Magni scripta varia.

Alb Autogr. Animal. $=$ Alberti autographa animalium historia. Conf. pag. 672 .

Avic - Avicennae Liber Canonis. Conf. pag. 189.

$\left.\begin{array}{l}\text { Avic. lat. } \\ \text { Avic. vet. }\end{array}\right\}=$ eiusdem libri editiones latinae et veteres.

Avic. arab. $=$ eiusdem libri editio arabica a Meyero conferts.

Barthol. = Bartholomaens Anglicus.

Cantipr. vide Thom.

$E d d$. = Editio utraque $\mathbf{J}$ et Z. Conf. pag. 669.

Isid. Orig. = Isidori hispalensis Origines.

Petr. = Petri de Crescentiis Opus ruralium commodorum. Conf. pag. 667.

Plemp. = Avicennae Canon interprete Plempio Lovanii 1658 editum.

Reliq = Codices reliqui.

Thom. = Thomas Cantipratensis in libro inedito: De naturis rerum.

Vocab. simpl. - Vocabularius simplicium. Conf. ind. pers.

De reliquorum autorum nominibus indicem personarum adeas. Varias plantarum aliorumque nominum scripturas ultimo plerumque loco, praesertim lib. VI, ascriptas reperies. 